\title{
Redesign an Oil Pump - Model Solution to a Student Project
}

\author{
Patrick J. Heffernan and W. Ernst Eder
}

\section{Introduction}

The Royal Military College of Canada is still influenced by historic conditions, where a transfer of students among the then-existing three colleges was mandated at the end of second year. Consequently, engineering studies occupied the final two years with only marginal reach into second year.

In Mechanical Engineering, a compulsory thirdyear course, MEE/GMF 303, was instituted in 1992, based on the concepts of Engineering Design Science [1] and its contributing works $[2,3,4,5]$. We follow the edict of Klaus [6] in cybernetics, that 'both theory and method emerge from the phenomenon of the subject'. Close relationships should exist between the subject under consideration (its nature as a concept, product, artifact or process), the basic theory (formal or informal, recorded or in a human mind), and the recommended method. Lectures about the theory and contexts of design engineering (usually one period per week) are accompanied by two mini-projects (about four periods per week). These are used during the course to teach the students the fundamentals of a technical system, the design process and engineering decisions, analysis and evaluation.

This paper describes a model solution for the first of the student mini-projects, involving the redesign of an oil pump for an internal combustion engine. The project is facilitated by the course instructor who walks the students through the intricacies of the design process. The project starts with writing a design specification for an oil pump as required for a modern car engine. Diagrams of organ and organ-group structures for an existing oil pump are prepared, and functions recognized. The design process results in the development of a function structure for the new pump and associated morphological matrix. Design options are derived from the morphological matrix and evaluated using evaluation criteria derived from the design specification. The paper describes the oil pump redesign problem as presented to the students and describes in detail the development of the model solution.

\section{References}

[1] Hubka, V., \& Eder, W.E. (1996) Design Science: Introduction to the Needs, Scope and Organization of Engineering Design Knowledge, London: Springer-Verlag, http://deseng.ryerson.ca/DesignScience/

[2] Hubka, V., \& Eder, W.E. (1988a) Theory of Technical Systems, New York: Springer-Verlag

[3] Hubka, V., \& Eder, W.E. (1992) Engineering Design, Zürich: Heurista

[4] Hubka, V., Andreasen, M.M., \& Eder, W.E. (1988b) Practical Studies in Systematic Design, London: Butterworths

[5] Eder, W.E. (ed) (1996) WDK 24 -- EDC -Engineering Design and Creativity -Proceedings of the Workshop EDC, Zürich: Heurista

[6] Klaus, G. (1965) Kybernetik in philosophischer Sicht (Cybernetics in Philosophical View) 4th ed., Berlin: Dietz Verlag 